\title{
LEI GERAL DE PROTEÇÃO DE DADOS: IMPACTOS NORMATIVOS NO DIREITO EMPRESARIAL
}

\author{
GENERAL DATA PROTECTION LAW: NORMATIVE IMPACTS ON BUSINESS \\ LAW
}

\author{
Orides Mezzaroba ${ }^{1}$ \\ André Lipp Pinto Bastos Lupi \\ Lucas Amaral Dassan ${ }^{3}$
}

\section{RESUMO}

O contexto abordado na pesquisa está ligado à análise dos aspectos da Lei Geral de Proteção de Dados e sua correlação com o Direito Empresarial. Também tem como foco a análise dos impactos econômicos que a referida legislação poderá trazer, à luz da análise econômica do direito, especificamente no que diz respeito ao panorama das transformações ensejadas pela economia globalizada, contemporânea, vinculada à velocidade e publicidade das trocas de informações e de dados, inclusive pessoais. Indubitavelmente as questões regulamentares das normas jurídicas conferem influência e transformações que afetam o dia-a-dia de todos os sujeitos de direitos e em especial à ordem econômica, pois necessárias adaptações desses sujeitos aos ditames regulamentares que determinada norma impõe. Neste contexto, o alto grau de tecnologia e de conectividade entre entidades, pessoas e empresas e o acesso aos dados de forma quantitativa, acabam por ensejar novas relações jurídicas e novas necessidades quanto à maneira de abordagem e regulamentação das referidas relações. Assim é que, de um lado, a legislação é adaptada com a finalidade de promover eficácia e eficiência ao rol de garantia e direitos, atendendo à clássica concepção de regramento dos fatos e valores sociais. Em contrapartida, as adaptações sociais e procedimentais dos sujeitos de direitos e obrigações ocasionam também consequenciais econômicas, especialmente quando carregadas de grau de responsabilidade caso não efetivem determinadas condutas, como no caso das diversas

\footnotetext{
${ }^{1}$ Professor Titular em Dedicação Exclusiva nos Programas de Graduação e Pós-Graduação em Direito (Mestrado e Doutorado) da Universidade Federal de Santa Catarina. Coordenador do Mestrado Profissional em Direito da Universidade Federal de Santa Catarina. Possui Graduação em Direito pela Pontifícia Universidade Católica do Paraná (1986). Especialização em Filosofia da Educação pela Pontifícia Universidade Católica do Paraná (1989). Mestrado em Direito pela Universidade Federal de Santa Catarina (1991). Doutorado em Direito pela Universidade Federal de Santa Catarina (2000). Pós- Doutorado junto à Universidade de Coimbra - Portugal (2008).

2 Possui graduação em Direito pela Universidade Federal de Santa Catarina (1997), mestrado em Direito pela Universidade Federal de Santa Catarina (2000) e doutorado em Direito pela Universidade de São Paulo (2006), com estágio doutoral no Institut de Hautes Études Internationales de Genebra. Realizou Estágio Pós-Doutoral na Universidade de Lisboa (2016-2017). Atualmente é professor do Programa de Mestrado em Direito Empresarial do Unicuritiba. Professor associado do Centro Universitário de Brasília (UniCeub). Foi Professor de Direito Empresarial da Universidade Federal de Santa Catarina, professor da Universidade do Vale do Itajaí, nos programas de Mestrado e Doutorado em Ciência Jurídica e de graduação em Direito e Relações Internacionais. Professor convidado do Doutorado em Ciência Jurídia da Pontificia Universidade Javeriana de Bogotá.

${ }^{3}$ Mestrando em Direito Empresarial e Cidadania no Centro Universitário Curitiba - UNICURITIBA. Curitiba PR. Possui graduação em Direito pelo Centro Universitário Curitiba (2006). Detém Especialização pela PUC/PR em Processo Civil Contemporâneo (2008) e, na mesma universidade, Especialização em Direito Civil e Empresarial (2014). E-mail: lucasdassan@ hotmail.com
} 
previsões expostas na Lei Geral de Proteção de Dados. Referida legislação traz um cabedal de procedimentos e modos de operar que afetam, especialmente, as empresas como um todo. Sob o viés dos pressupostos indicados, questiona-se: Quais as especificidades da Lei Geral de Proteção de Dados que dizem respeito à atuação empresarial? Quais os impactos e consequências dessas especificidades, sob o ponto de vista da análise econômica do direito, para o Direito Empresarial? O presente trabalho tem por objetivo geral a proposição da análise da interação entre a Economia e o Direito Empresarial, bem como dos institutos vinculados à Lei de Proteção de Dados, relativos aos impactos para adaptação das empresas.

Palavras-chave: Lei Geral de Proteção de Dados; Direito Empresarial; Economia e Direito.

\section{ABSTRACT}

The context addressed in the research is linked to the analysis of aspects of the General Data Protection Law and its correlation with Business Law. It also focuses on the analysis of the economic impacts that such legislation may bring, in light of the economic analysis of law, specifically with regard to the panorama of the transformations brought about by the globalized, contemporary economy, linked to the speed and publicity of the exchange of information and including personal data. Undoubtedly the regulatory issues of legal norms confer influence and transformations that affect the daily lives of all subjects of rights and especially the economic order, as these subjects need to adapt to the regulatory dictates that a particular rule imposes. In this context, the high degree of technology and connectivity between entities, people and companies and the access to data in a quantitative way, end up giving rise to new legal relationships and new needs regarding the approach and regulation of these relationships. Thus, on the one hand, the legislation is adapted in order to promote effectiveness and efficiency to the list of guarantee and rights, taking into account the classic conception of rules of social facts and values. On the other hand, the social and procedural adaptations of the subjects of rights and obligations also cause economic consequences, especially when charged with a degree of responsibility if they do not perform certain behaviors, as in the case of the various provisions set forth in the General Data Protection Act. Said legislation brings a range of procedures and modes of operation that especially affect companies. Under the bias of the indicated assumptions, the following questions are asked: What are the specificities of the General Data Protection Law that concern business performance? What are the impacts and consequences of these specificities, from the point of view of the economic analysis of law, on business law? The present work has as general objective the proposition of the analysis of the interaction between the Economy and the Business Law, as well as of the institutes linked to the Data Protection Law, concerning the impacts for the adaptation of the companies.

Key-words: General Data Protection Act; Business law; Economics and Law.

\section{INTRODUÇÃO}

Através de um breve olhar sobre o cotidiano das sociedades contemporâneas é possível perceber grandes transformações, em especial tecnológicas, as quais ocorrem em breves espaços de tempo. A quantidade de informações e dados produzidos atualmente é significativa tanto do ponto de vista pessoal como do ponto de vista coletivo. Os aspectos sociais são cada vez mais realinhados pela prática do consumo em massa e pelas novas sistematizações das 
relações interpessoais. A conectividade entre sujeitos, a troca massiva de informações, a colheita robusta de dados, a rapidez mercadológica e o desenvolvimento de tecnologia, vinculados aos fenômenos sociais e econômicos, são exemplos dessas mudanças que estão ocorrendo em velocidade temporal acima do que anteriormente era auferível.

Sobre as transformações no campo jurídico, é possível afirmar que os efeitos dessas modificações sociais e econômicas geram reflexos na ordem normativa, influenciadas justamente pelo contexto econômico cultural em que se inserem.

De forma mais específica quanto a esta pesquisa, realizando a subsunção desse contexto ao tema indicado, é possível vislumbrar que as modificações das relações entre sujeitos ocasionam a necessidade de um redobrado entendimento e aprimoramento do estudo acerca dos institutos normativos inovatórios que tendem a regulamentar os aspectos mais contemporâneos da sociedade, já que impactam nas formas de adaptações que todos os membros sociais precisam concretizar.

A grande questão abordada neste estudo está ligada à descrição dos principais aspectos da Lei Geral de Proteção de Dados que influenciam as condutas empresariais e a análise da interação existente entre o direito e a economia no que diz respeito à adaptação das empresas frente a essa forma de regulamentar a proteção dos dados.

Por conta disso é que o trabalho elenca as seguintes questões nodais: Quais as especificidades da Lei de Proteção de Dados que dizem respeito à atuação empresarial? Quais os impactos e consequências dessas especificidades, sob o ponto de vista da análise econômica do direito, para o Direito Empresarial?

Por este aspecto, utiliza-se do método dedutivo, analítico e descritivo para construção do trabalho em análise. Dedutivo, pois é observado um fenômeno geral atinente à interação entre o Direito e a Economia, desdobrando-se na observação de determinados efeitos, especificamente na esfera privada atinente à atuação das empresas em razão da Lei de Proteção de Dados; Analítica, pois percorre o estudo e avaliação da natureza jurídica dos institutos; Descritiva, pois salienta a opinião de diversos doutrinadores sobre o assunto em pauta, contribuindo para a análise dos pontos comuns.

A discussão que é sugerida se faz relevante com a finalidade de averiguar os efeitos derivados da adaptação (ou da necessidade de renovação) das empresas à regulamentação correlata. 


\section{INTERAÇÃO ENTRE DIREITO E ECONOMIA: A ANÁLISE ECONÔMICA DO DIREITO ENVOLVENDO A ATIVIDADE EMPRESARIAL E OS IMPACTOS NORMATIVOS}

$\mathrm{Na}$ atualidade e em conformidade com o que lança à luz Eduardo Bittar, as principais teorias que se enquadram na definição do Direito se inserem na concepção de sistema (BITTAR, 2008). É possível vislumbrar o Direito sob a abordagem da Teoria dos Sistemas de Niklas Luhmann, da Teoria do Discurso de Habbermas e também sob a análise da Teoria da Semiótica.

Com base na conexão das referidas teorias, de forma resumida e adequada ao objeto deste estudo, é possível indicar que o Direito se mostra como uma Ciência que reúne diversificados enquadramentos de concepções sociais, como expõe a Teoria Tridimensional do Direito de Miguel Reale (REALE, 2008), sendo fenômeno social permeado de um conjunto de Normas, Fatos Sociais e Valores que interagem entre si de forma dialética.

Porém, o Direito também pode ser alinhado como um Sistema Autopoiético e que se relaciona com outros sistemas, através de uma rede de interações simbólicas, conforme a teoria da comunicação e da linguagem, inclusive sob o ponto de vista da semiótica jurídica (BITTAR, 2018, p. 421).

O fenômeno do Direito, nesta concepção, perfaz-se como um sistema interativo que exerce extensão e que é influenciado por outras ciências e fenômenos diversos, inclusive aqueles ligados aos fatos sociais, como ocorre com a Economia.

A Economia, por sua vez, é uma Ciência que também se abeira claramente da movimentação de situações que ocasionam modificações em seu conteúdo, tais como fatos sociais, culturais e tecnológicos, conferindo-lhe autonomia e status de microssistema, o qual também exerce influência em relação a outros ramos envolvendo fenômenos sociais.

Robert Helbroner e Lester Thurowe (2005), salientam que desde o surgimento da sociedade de mercado e o desencadeamento tecnológico que culminou na revolução industrial, a economia e as modificações mercadológicas tomaram rumo acelerado, culminando em uma sistemática de globalização exponencial.

As modificações indicadas trazem duas consequências diretas envolvendo: a) necessidade de intervenções regulamentares nas relações através de inovações normativas e; b) aparecimento de novos paradigmas e novos institutos que permitem a adaptação dos sujeitos de direito no ramo de atuação social. 
Decio Zylbersztajn e Rachel Sztajn (2005), destacam neste sentido que:

O sistema econômico é um conjunto de relações entre pessoas físicas e jurídicas e seu desempenho depende, em sua essência, do modo como essas relações ocorrem. Reside aqui a importância dos contratos para a análise econômica. Contratos estabelecem o padrão de comportamento, expresso na forma de um conjunto de deveres, que as partes definem por interesse mútuo. E, portanto, por meio de contratos que as pessoas buscam coordenar as suas ações, realizando ganhos coletivos. Como as transações apresentam custos diversos, um contrato que atenue esses custos resulta em melhora de desempenho econômico das firmas e mercados, com implicações diretas ao desenvolvimento econômico e social. A aproximação entre Economia e Direito é uma necessidade imposta por conta das novas e relevantes questões que emergem na literatura econômica.

Há, portanto, forte interação entre o Direito e a Economia, pela mútua influência que se exercem.

Paula Forgini (2006, p. 35-61) indica que um dos préstimos da Análise Econômica do Direito seria justamente a identificação dos efeitos de determinada norma jurídica, traçandose uma relação entre custo benefício das políticas jurídicas, tal qual ocorre no presente caso estudado em que há uma inovação legislativa que culmina em consequências significativas para os sujeitos que a ela se submetem.

Pertinentes, neste sentido, os comentários de Diogo de Figueiredo Moreira Neto (apud WALD, 2003, p. 23) que destaca:

O novo direito se plasma como resultado insopitável da pressão das novas demandas de um mundo contemporâneo e os Estados tem que abrir espaço às sociedades, em que deixam de ser a única fonte normativa [...] na ciência jurídica, o positivismo jurídico cede vez ao pós-positivismo e passa a exigir que o direito volte a conter valores e a lei, uma das formas de exprimi-lo, admitindo-se o pluralismo das fontes normativas.

A referida afirmação de trocas mútuas entre Direito e Economia deságua na conclusão de que o Direito em si pode (e até mesmo deve) ser interpretado também à luz de uma "análise econômica".

Referida tendência tem como escopo a observação analítica de institutos jurídicos sob o prisma do valor agregado, da utilidade e da eficiência, bem como das forças consequentes que os referidos institutos ocasionam no mundo dos fatos, especialmente aqueles que estão 
atrelados às questões financeiras e econômicas como atinentes aos conceitos de custos e investimentos.

Nesta linha de raciocínio pode ser elencado que:

[...] a Análise Econômica do Direito é essencialmente um movimento interdisciplinar, que traz para o sistema jurídico as influências da ciência social econômica, especialmente os elementos "valor", "utilidade" e "eficiência". Busca aplicar seu método a todas as searas do direito, apresentando um novo enfoque de forma dinâmica - desde aquelas em que é fácil vislumbrar a inter-relação, como o direito da concorrência e contratos mercantis- até naquelas em que causa maior estranheza para o jurista, como no direito penal e relações familiares (GALESKI JUNIOR; RIBEIRO, 2015, p. 83).

Desses raciocínios, certo perceber que as modificações socioeconômicas afetam sensivelmente o campo do Direito sendo que a recíproca é verdadeira, fazendo com que determinados institutos jurídicos acabem impactando a rotina e procedimentos dos sujeitos que estão a eles submetidos, gerando consequências também de cunho econômico.

\section{ESPECIFICIDADES DA LEI GERAL DE PROTEÇÃO DE DADOS PARA O DIREITO EMPRESARIAL}

A interação entre Direito e Economia é uma constante. Enquanto as transformações econômicas trazem consequenciais para a vida em sociedade, ocasionando modificações nas relações entre sujeitos de direitos e obrigações, influenciando os fatos sociais a ponto de ensejarem regulamentações normativas; o Direito, por sua vez, justamente através da inserção de princípios e regras que permeiam a sociedade, também exerce impacto na economia, especialmente no que diz respeito às adaptações que devem ser despendidas pelos envolvidos com a finalidade de alinharem a forma de sua atuação perante a sociedade.

$\mathrm{Na}$ contemporaneidade, especificamente no campo empresarial onde imperam relações em quantidades abundantes, concernentes à interação entre empresas e consumidores diretos ou equiparados, bem como entre as próprias empresas por meio de negócios jurídicos interempresariais, coexistem trocas constates de informações e dados. A situação ganha volatilidade e abstração significativa em razão da conectividade e velocidade que trazem os meios de comunicações atuais, especialmente em razão da tecnologia que avança a passos largos. 
Em estudo realizado sobre privacidade, internet e dados pessoais, Victor Drummond salienta que:

A nova sociedade da informação seria uma congregação de tecnologias de tal modo relacionadas entre si que o mundo contemporâneo teria acesso a quantidade de informações sequer imaginado em outras épocas. É verdade. Nunca se viu um acesso tão grande, tão facilitado à informação como poderemos observar na atualidade (DRUMMOND, 2003, p. 1).

Neste diapasão corriqueiro em que se sustenta a típica concepção da modernidade líquida exposta por Zygmunt Habbermas (2001), onde as conjunturas da vida em sociedade se perfazem rápidas, dinâmicas, sem que exista um local sólido de existência ou que se sustente efetivamente ao longo do traspassar do tempo, vinculadas de certa forma ao padrão de consumo constante e em quantidades, revelam-se relações, inclusive negociais, dentro da mesma estirpe. Evidenciam-se, portanto, redes de interações cada vez mais constantes, mas que se desfazem com a mesma velocidade.

Norberto Bobbio (2004, p. 231) elenca com precisão ao indicar que:

[Atualmente é vivida a] sensação da aceleração dos tempos que, por sua vez, pertence à geração nascida na era da tecnológica, para qual a passagem de uma fase à outra do progresso técnico, que antigamente demorava séculos, depois décadas, agora demora poucos anos [...] $\mathrm{O}$ tempo vivido não é o tempo real.

Assim, no contexto do dinamismo dos fatos sociais, chama a atenção a necessidade de resguardo à efetividade dos direitos fundamentais que normalmente estão abrigados em normas e princípios de cunho mais abstratos, inseridos na Constituição.

A revaloração dos fatos sociais ou a valoração de novos fatos sociais impingem a necessidade de tratamento mais concreto aos direitos e garantias que são cunhados como fundamentais. Neste sentido, vislumbram-se inovações legislativas infraconstitucionais que possuem o objetivo proposto.

$\mathrm{Na}$ ordem da contemporaneidade, como vislumbrado, está em voga a necessidade de regulamentação de aspectos atinentes a esta sociedade dinâmica, conectada, desdobrando-se proteções aos sujeitos inseridos neste novo mundo tecnológico, de intensa rapidez nas relações e nas trocas de informações. 
Assim, são promulgadas normas com tendências a regulamentar referidos aspectos, tais como ocorreu com a Lei do Marco Civil da Internet e a Lei Geral de Proteção de Dados, objeto do presente estudo.

Inobstante a dicotomia acerca dos reais limites para exercício da regulamentação dos fatos sociais atinentes ao mercado (pois de um lado há a necessidade de resguardo concreto de direitos e garantias ,e de outro, também na atualidade, há intensa manifestação para manutenção do modelo liberal de mercado) é certo perceber que o Direito estará sempre presente para amoldar os regramentos concernentes às relações mais agudas e intensas.

No contexto social em que o Brasil está inserido, levando os aspectos antes salientados envolvendo a massificação das relações e as trocas informacionais, adveio preocupação por parte do legislador em relação aos direitos fundamentais da personalidade dos indivíduos abstratamente inseridos na Constituição, especialmente relativos aos dados personalíssimos.

A tendência, na realidade, seguiu os ditames daquilo que já vem estabelecido em outros países e blocos econômicos como a União Europeia que, desde 1995, vinha se preocupando com as indicadas circunstâncias. Naquela época já havia sido promulgada a denominada Diretiva 95/46/CE e suas respectivas transposições para leis nacionais dos países membros. Subsequentemente, desde 2016, a União Europeia conta com um contemporâneo Regulamento que substituiu a diretiva anteriormente indicada: trata-se do Regulamento (EU) 2016/679 do Parlamento Europeu e do Conselho.

Culminando na elevada importância da proteção dos dados pessoais, explica-se que:

[...] cabe [...] a devida atenção a um ponto especificamente delicado, qual seja: a denominada proteção dos dados pessoais. Com efeito a tecnologia permite o cruzamento, rápido e eficiente, de dados pessoais geradores de informações de diversas modalidades. Assim, pode rapidamente traçar o perfil (ou meramente - "um perfil") de uma pessoa, ainda que não seja o seu perfil correto. Os dados coletados, o que pode vir a ser aprioristicamente desimportantes, herdam, em decorrência da tecnologia, uma importância antes imaginada (e inimaginável!). A tecnologia deixa o cidadão comum à mercê das corporações e dos governos no que diz respeito à manutenção, ou ainda, à manipulação dos dados e informações a si referentes (DRUMMOND, 2003, p. 5).

\footnotetext{
${ }^{3}$ UNIÃO EUROPEIA. Diretiva 95/46/CE do Parlamento Europeu e do Conselho, de 24 de Outubro de 1995. Relativa à proteção das pessoas singulares no que diz respeito ao tratamento de dados pessoais e à livre circulação desses dados. Luxemburgo, out 1995.

${ }^{4}$ UNIÃO EUROPEIA. Regulamento (UE) 2016/679 do Parlamento Europeu e do Conselho, de 27 de abril de 2016. Relativa à proteção das pessoas singulares no que diz respeito ao tratamento de dados pessoais e à livre circulação desses dados e que revoga a Diretiva 95/46 / CE (Regulamento Geral de Proteção de Dados). Bruxelas, abr 2016.
} 
Assim, no Brasil, a Lei $\mathrm{n}^{\circ} 13.709$ de Agosto de $2018^{5}$ dispõe exaustivamente sobre o tratamento de dados pessoais, inclusive nos meios digitais, por pessoa natural ou jurídica de direito público ou privado. Ademais, referidos aspectos estão contidos justamente no primeiro artigo da legislação.

Ademais, justamente no mesmo dispositivo inicial, o legislador traceja o objetivo especial de proteção de três direitos fundamentais que reverberam efeitos por toda a normativa em questão: a) o direito de liberdade; b) o direito de privacidade e; c) o direito ao livre desenvolvimento da personalidade da pessoa natural.

Expressamente também são elencados os fundamentos sobre os quais se sustentam toda a disciplina de proteção dos dados, onde estão inseridos conceitos jurídicos vinculados aos direitos e garantias fundamentais, porém com roupagem mais contemporânea. Assim é que são elencados o respeito à privacidade, a autodeterminação informativa, a liberdade de expressão, o direito de informação, de comunicação e de opinião, a inviolabilidade da intimidade, da honra e da imagem, o desenvolvimento tecnológico e a inovação, a livre iniciativa, a livre concorrência e a defesa do consumidor, bem como os direitos humanos, o livre desenvolvimento de personalidade e o exercício da cidadania pelas pessoas naturais.

A legislação em questão visa atingir o maior escopo possível de relações que envolvam o tratamento de dados, aplicando-se de maneira abrangente, contendo apenas algumas exceções expostas de maneira taxativa a fim de não prejudicar situações de livre expressão para fins exclusivos (como em situações acadêmicas, jornalísticas e artísticas) ou que submerjam conjunturas de segurança pública (como situações investigativas ou de segurança nacional).

Cumpre observar que o objeto da legislação em questão se perfaz justamente em relação ao tratamento de dados pessoais, circunstância que desdobra uma infinidade de consequências para os envolvidos.

A sistemática estabelecida para o tratamento de dados pessoais está dívida em categorias que evidenciam ordem de proteção ou especificidade de proteção. Assim, desdobram-se as regras para tratamento de dados pessoais gerais, dados classificados como sensíveis e também aqueles que são de titularidade de crianças e adolescentes. Há, ainda, indicações acerca do término do tratamento dos correlatos dados, inclusive regras que padronizam a necessidade de exclusão dos dados, após o tratamento correlato.

\footnotetext{
${ }^{5}$ BRASIL. Lei no 13.709, de 30 de ago de 2018. Lei Geral de Proteção de Dados Pessoais (LGPD). Brasília, DF, ago 2018.
} 
A legislação em análise estabelece uma série de direitos aos titulares respectivos, incluindo-se possibilidades de solicitações acerca de acesso, correções, eliminações e obtenções de informações específicas. Há previsão acerca dos desdobramentos procedimentais que devem ser adotados por aqueles que estão efetivando o tratamento dos dados, evidenciando necessidade de aparato estrutural para atendimento condizente.

A existência de capítulo específico para o tratamento dos dados pessoais pelo Poder Público corrobora a abrangência da Lei, contendo determinações próprias e estabelecendo consequências procedimentais de grande importância.

Em capítulo específico são observadas as regras para transferência internacional de dados, cujo aparato é de grande impacto geral relativo às relações entre países e, especialmente, às relações comerciais, vinculando-se referida perspectiva à luz do Direito Internacional e até mesmo sob aspectos do Comércio Internacional.

Ponto nevrálgico da legislação em referência é o de criação ou de manutenção de estruturas internas ou externas pelos sujeitos que exercem os tratamentos de dados, as quais serão responsáveis pelas atividades envolvendo os dados pessoais de terceiros. A Lei faz indicação da figura do Controlador, do Operador e do Encarregado pelo tratamento de dados pessoais, cada qual com funções específicas.

Interessante ressaltar que os referidos agentes, salvo determinadas exceções também previstas na legislação, terão responsabilidade em razão do exercício das atividades de tratamento de dados pessoais quando causarem danos patrimoniais, morais, individuais ou coletivos. Ademais, correlata responsabilidade se dará de forma solidária.

Restam estabelecidas indicações de boas práticas e de governança em que são elencados diversos procedimentos e programações relativas às atividades de tratamento de dados, envolvendo políticas internas, planos, mecanismos de supervisões das atividades, tudo envolvendo também o aspecto de publicidade quanto a esses elementos, com a finalidade de transparecer maior segurança jurídica nas tarefas exercidas perante a coletividade.

Subsequentemente, a legislação traça um arcabouço relativo às sanções administrativas que podem ser aplicáveis aos agentes de tratamento de dados que poderão ser de inúmeras espécies, entre elas a advertência, a multa simples e a multa diária. As sanções, importante ressaltar, poderão chegar a cinquenta milhões de reais.

Por fim, a Lei cria a Autoridade Nacional de Proteção de Dados e o Conselho de Proteção de Dados Pessoais e da Privacidade, com competências específicas para avaliar, analisar condutas, realizar estudos e resguardar a aplicação da legislação em referência. 
Conforme descrito, é possível perceber que a legislação em tela adotou um posicionamento extremamente garantista, já que além dos tratamentos de dados gerais e que são meramente nominativos, também regra pormenores quanto aos tratamentos de informações classificadas como sensíveis, sendo que as tarefas que abarcam todas as estirpes de dados só serão possíveis com o consentimento de seu titular, assegurando-lhe ainda a possibilidade de anotação (SILVA; MELO, 2019. p. 354-377). Indica-se, portanto, que a legislação em referência confere primazia à autonomia privada, na mediada em que concretiza a privacidade como um direito à “autodeterminação informativa" (SILVA; MELO, 2019. p. 354-377).

Em contrapartida, especificamente quanto aos aspectos também vinculados ao objetivo do presente estudo, é possível verificar que o arcabouço de regras estabelece uma série de obrigações concernentes à procedimentos e estruturação por parte daqueles que irão efetivar o tratamento de dados.

Neste diapasão, elenca-se que grande parte dos sujeitos que deverão adotar as correlatas práticas são empresas, justamente por estarem inseridas em um mercado dinâmico e tecnológico, conforme exposto em tópico anterior, onde a massificação de dados e informações é regra geral.

Assim, a adaptação respectiva com a assunção de responsabilidades se perfaz de maneira impactante tanto do ponto de vista econômico quanto do ponto de vista da gestão e da governança empresarial.

\section{IMPACTOS NORMATIVOS E ECONÔMICOS DA LEI GERAL DE PROTEÇÃO DE DADOS PARA AS EMPRESAS}

Conforme indicado anteriormente, a aplicação da legislação em questão é vasta. Referida incidência de âmbito abrangente se perfaz como de importante análise, pois insere todos os sujeitos que acabam tratando dados de pessoas naturais ao regramento correlato, confirmando impactos atinentes aos processos internos e também consequências econômicas para que sejam possíveis as respectivas adaptações.

Neste contexto, é possível perceber que a legislação em questão atinge fortemente as empresas, já que inseridas no dinamismo social em que os dados de seus clientes, consumidores ou demais pessoas naturais que se relacionam estão sob a proteção do seu arcabouço. 
É certo salientar que a correlata apreciação, vinculada aos impactos de gestão e estruturação para atendimento de normativas jurídicas, está inserida em um dos aspectos da denominada análise econômica do direito.

A Escola de Chicago, representada quanto ao tema por David Friedman (2000), influenciado por Milton Friedman, indica três propostas para análise econômica do direito: a) análise dos efeitos das normas; b) a análise quanto ao fundamento da norma e; c) a análise da norma mais eficiente em dado caso concreto.

No presente estudo o que se pretende é alertar para as consequências dos efeitos da norma em relação às adaptações necessárias a serem realizadas pelas empresas quanto ao tratamento de dados pessoais, neste caso vigorosamente vinculados às informações individuais dos seus clientes e consumidores diretos ou equiparados.

Neste contexto, chama a atenção três pontos nodais da Lei Geral de Proteção de Dados que acabam trazendo maiores consequenciais do ponto de vista da gestão empresarial, da governança corporativa e de investimento em estrutura: a) a estruturação geral para atendimento eficaz e eficiente ao tratamento de dados, garantindo a sua proteção; b) a criação ou contratação de agentes que realizarão o correlato tratamento e; c) as indicações procedimentais elencadas no capítulo da lei que trata das boas práticas e da governança.

Marcia Carla P. Ribeiro e Irineu Galesko Junior (2015, p. 94) salientam aspectos acerca da intervenção do Estado (aqui considerando também a intervenção por meio das normas jurídicas que causam impactos adaptativos no mercado) indicando que a intervenção correlata acaba gerando custos, já que espelham incentivos ou proibições para as relações. Salientam, todavia, que inobstante as referidas consequências, a intervenção deve ocorrer para que sejam eliminadas falhas de mercado. Como exemplos de intervenções para saneamento dessas falhas de mercado é possível indicar a busca para se evitar o abuso do poder econômico ou, como de interesse deste estudo, lesões a determinados direitos como no caso de utilização indevida dos dados personalíssimos.

Conforme delineado, as adaptações de cunho estruturais e procedimentais nas empresas são significativas quanto aos aspectos da Lei Geral de Proteção de Dados, sendo interessante descrever e analisar os três pontos nodais destacados anteriormente.

O primeiro ponto diz respeito à estruturação geral para atendimento eficaz e eficiente ao tratamento de dados, garantindo a sua proteção.

Neste contexto, há necessidade de implantação de banco de dados que permitam o tratamento, o armazenamento, a anonimação, o consentimento dos titulares, a eliminação e o 
uso compartilhado dos dados, exigindo-se também arcabouço procedimental jurídico com a finalidade de atingir os objetivos respectivos, como por exemplo, a inserção de cláusulas contratuais que estejam alinhadas com a legislação. A norma faz referência, ainda, ao necessário relatório de impacto à proteção de dados que poderá ser requisitado pela autoridade responsável para avaliações. Assim, é possível observar impactos no que diz respeito às questões de políticas jurídicas internas das empresas, nos processos internos e na estruturação tecnológica.

Quanto ao segundo ponto, acerca da criação ou contratação de agentes que realizarão o tratamento dos dados, a Lei confere especificações claras sobre os respectivos sujeitos, inclusive salientado os níveis acerca da responsabilidade civil que, neste caso, perfaz-se solidária. Cumpre perceber que a legislação impõe a utilização de sujeitos responsáveis pelo tratamento de dados, reverberando efeitos no sentido de que as empresas terão que realizar nomeações internas ou concretizar a terceirização de atividade para especialistas técnicos que cuidarão dos indicados aspetos. Por óbvio também que em todas essas opções, toda uma sistemática de procedimentos deverá ser amoldada, sendo que também haverá alocações de recursos para que se dê concretude às exigências.

Sobre o terceiro aspecto, envolvendo as indicações legais procedimentais elencadas no capítulo que trata das boas práticas e da governança, especificadas especialmente no artigo 50 da lei em referência, ficam estampadas as ações necessárias para adaptação interna nas empresas, mas neste caso o legislador salientou aspectos facultativos, pois sempre emprega o termo "poderá" quando indica as referidas normas. Todavia, como as preconizadas atividades estarão ligadas a uma espécie de autorregulação das empresas, muitas vezes unidas às normativas internas de compliance, provavelmente serão adotadas pela gestão corporativa, até porque derivarão das atividades dos agentes que realizarão o tratamento de dados (Controlador, Reparador e Encarregado).

Em todas conjunturas há necessidade, por parte das empresas, de alocação de recursos, investimentos, sistematizações, alterações de procedimentos internos, criações de setores, departamentos ou necessidade de terceirização, bem como de treinamento de colaboradores, investimentos em equipamentos e tecnologias, observando-se impacto de amplo espectro advindos da regularização do Estado por via da inserção de normas jurídicas que tem por objetivo a concretização de direitos fundamentais em face da dinâmica informacional e da hipossuficiência dos seus titulares em relação ao aparato tecnológico vinculado à sociedade de risco. 
Assim, é possível antever, sob o prisma da análise econômica do direito, os efeitos da correlata norma sobre as empresas, reverberando consequências para o mundo empresarial.

\section{CONSIDERAÇÕES FINAIS}

O mundo contemporâneo é baseado em uma dinamicidade tecnológica e comunicativa constante, onde imperam as trocas massivas de dados e informações, desdobrando-se na necessidade da análise dos fenômenos econômicos à luz do direito e os fenômenos jurídicos, em reciprocidade, serem analisados à luz da economia.

Colossal é a interdisciplinaridade e a influência recíproca entre a Economia e o Direito, observando-se referida interação pela lógica de diversas teorias atuais, especialmente pela teoria dos sistemas, revelando o nível acurado de correspondência semiótica entre os referidos campos.

Com fundamento na evolução constante da economia e na interação de diversos sujeitos envolvidos na arena social, inovando-se as formas de relações, permanece a constante necessidade de regularização e normatização por parte do Estado, com a finalidade de dar concretude a direitos e obrigações que devem estar ligados aos direitos e garantias abstratamente tutelados, via de regra, pela Constituição.

Por esta trilha, entram em voga o aparecimento de legislações que visam tutelar as novas formas de relações, como ocorre com a Lei Geral de Proteção de Dados, cujo objetivo se faz bem traçado para os tempos contemporâneos em que as informações e dados pessoais estão pulverizados em ambientes diversos, tanto físicos como virtuais, compartilhados de maneira significativa entre os agentes do mercado.

Sob o prisma de uma análise econômica do direito, é possível descrever e analisar, entre outros aspectos, os efeitos dessas normas inovadoras frente à economia e aos agentes que são influenciados pela normatização.

Conforme delineado no presente estudo, a Lei Geral de Proteção de Dados traz em seu arcabouço legal uma série de consequências para os agentes que lhes estão sujeitos, especificamente para as empresas, sendo indicadas séries de peculiaridades que envolvem a reestruturação de rotinas, de procedimentos, bem como treinamento de colaboradores, efetivações de novas contratações de pessoas, serviços e novas aquisições de equipamentos.

Da análise da Lei Geral de Proteção de Dados e do ponto de vista da gestão empresarial, da governança corporativa e de investimento em estrutura, neste estudo foram 
elencados três consequências principais às empresas, além de outras secundárias: a) a necessidade de estruturação geral para atendimento eficaz e eficiente ao tratamento de dados, garantindo a sua proteção; b) a criação ou contratação de agentes que realizarão o correlato tratamento e; c) necessidade de respeito às indicações procedimentais elencadas no capítulo da lei que trata das boas práticas e da governança.

Em todas conjunturas indicadas há necessidade, por parte das empresas, de alocação de recursos, investimentos, sistematizações e alterações de procedimentos.

Observa-se, portanto, impactos advindos da normatização realizada pelo Estado que tem por objetivo a concretização de direitos fundamentais em face da dinâmica informacional e da hipossuficiência dos titulares dessas informações em relação ao aparato tecnológico vinculado à sociedade de risco.

Apesar de não esgotadas todas as condições, o presente trabalho chega ao seu objetivo, respondendo as questões inicialmente elencadas, demonstrando peculiaridades acerca da Lei Geral de Proteção de Dados para as empresas, bem como os possíveis impactos imediatos para a correlata adaptação à legislação.

Por fim, possível salientar que todos os ajustes derivados da norma em estudo se perfazem de maneira significativa, tanto do ponto de vista econômico quanto do ponto de vista da gestão e da governança empresarial, demonstrando a interação entre Direito e Economia.

\section{REFERÊNCIAS}

BAUMAN, Zygmunt. Modernidade líquida. Traduzido por: Plínio Dentzien. Rio de Janeiro: Zahar, 2001.

BITTAR, Eduardo C. B. Introdução ao estudo do direito: humanismo, democracia e justiça. São Paulo: Saraiva, 2018.

BOBBIO, Norberto. A era dos direitos. São Paulo: Editora Campos, 2004.

BRASIL. Lei $\mathrm{n}^{\circ}$ 13.709, de 30 de ago de 2018. Lei Geral de Proteção de Dados Pessoais (LGPD). Brasília, DF, ago 2018.

BRUE, Stanley L. História do Pensamento Econômico. Tradução de: Luciana Penteado Miquelino. São Paulo: Thomson, 2005.

DRUMMOND, Victor. Internet, privacidade e dados pessoais. Rio de Janeiro: Editora Lumen Juris, 2003.

FORGIONI, Paula Andrea. Análise econômica do direito: paranoia ou mistificação? Revista do Tribunal Regional Federal da $3^{a}$ Região, São Paulo, n. maio/jun 2006, p. 35-61, 2006. 
FRIEDMAN, David. Law's Order: What Economics Has to do with Law and Why It Matters. Princeton, Princeton University Press, 2000.

HELBRONER, Robert; THUROW, Lester. Entenda a economia: Tudo o que você precisa saber sobre como funciona e para onde vai a economia. Tradução de: Tomás Rosa Bueno. Rio de Janeiro: Editora Campus, 2005.

MOREIRA NETO, Diogo de Figueiredo. Confronto e desafios num mundo globalizado - um enfoque juspolítico. In: WALD, Arnoldo; MARTINS, Ives Gandra; PRADO, Ney (Coord). O direito brasileiro e os desafios da economia globalizada. Rio de Janeiro: América Jurídica, 2003.

REALE, Miguel. Teoria tridimensional do direito. 5 ed. São Paulo: Saraiva, 2018.

RIBEIRO, Marcia Carla Pereira; GALESKI JUNIOR, Teoria geral dos contratos: Contratos empresariais e análise econômica. 2 ed. São Paulo: Revistas dos Tribunais, 2015.

SILVA, Lucas Gonçalves; MELO, Bricio Luis da Anunciação. A lei geral de proteção de dados como instrumento de concretização da autonomia privada em um mundo cada vez mais tecnológico. Revista Jurídica Unicuritiba. Vol. 03, nº. 56, Curitiba, 2019. pp. $354-377$.

UNIÃO EUROPEIA. Diretiva 95/46/CE do Parlamento Europeu e do Conselho, de 24 de Outubro de 1995. Relativa à proteção das pessoas singulares no que diz respeito ao tratamento de dados pessoais e à livre circulação desses dados. Luxemburgo, out 1995.

UNIÃO EUROPEIA. Regulamento (UE) 2016/679 do Parlamento Europeu e do Conselho, de 27 de abril de 2016. Relativa à proteção das pessoas singulares no que diz respeito ao tratamento de dados pessoais e à livre circulação desses dados e que revoga a Diretiva 95/46 / CE (Regulamento Geral de Proteção de Dados). Bruxelas, abr 2016.

ZYLBERSZTAJN, Decio (Org.); SZTAJN, Rachel (Org.). Direito e economia: Análise econômica do direito e das organizações. Tradução de: Tomás Rosa Bueno. Rio de Janeiro: Editora Campus, 2005. 